\title{
The inflammatory response of the gastric mucosa of mice experimentally infected with "Gastrospirillum suis"
}

\author{
SILVIA B. MOURA, DULCIENE M. M. QUEIROZ*, E. N. MENDES, ANA M. M. F. NOGUEIRA $\dagger$ \\ and G. A. ROCHA
}

Laboratory of Research in Bacteriology, $\dagger$ Department of Pathology, Faculdade de Medicina, Universidade Federal de Minais Gerais, Av. Alfredo Balena, 190 S.464, CEP 30130-100, Belo Horizonte, Minais Gerais, Brazil

\begin{abstract}
Summary. To establish an experimental model to study gastric spiral non-cultivable bacteria, 30 4-week-old female CFW (LOB) mice were inoculated with porcine gastric mucus containing "Gastrospirillum suis" and 25 mice were inoculated with mucus without " $G$. suis". Mice were examined 3, 7, 14, 21, 28 and 60 days after inoculation. Fragments from the membranous, oxyntic and antral gastric mucosa and from the duodenal mucosa were obtained for histological and microbiological analysis. Tightly spiralled bacteria were seen in smears and in histological sections of the antral and oxyntic mucosa from all G. suis-infected mice. The pre-formed urease test also gave positive results in both tissues. In control mice, no tightly spiralled bacteria were seen. By 7 days after inoculation, the test animals had developed an inflammatory infiltrate of mononuclear cells, some neutrophils and a few eosinophils, mainly in the lower third of the antral and oxyntic mucosa, which persisted for the remainder of the observation period. This model can assist in the understanding of several clinical, pathological and immunological aspects of infection with spiral gastric bacteria, particularly those associated with non-cultivable spiral bacteria.
\end{abstract}

\section{Introduction}

Helicobacter pylori is now recognised as the most important cause of gastritis in man, as well as an essential factor in the pathogenesis of duodenal ulcer. ${ }^{1}$ Another spiral bacterium distinct from $H$. pylori has also been detected in the antral mucosa of patients with active chronic gastritis. ${ }^{2}$ This tightly spiralled bacterium, formerly referred to as "Gastrospirillum hominis" by McNulty et al..$^{3}$ and now named $H$. heilmanii ${ }^{4}$ has not been studied extensively, mainly because it has not yet been cultured in the laboratory. Furthermore, many aspects of the association between H. pylori and human gastric mucosa are not fully understood, due in part to difficulties in conducting investigations into naturally occurring infections in man and to the restricted host range of $H$. pylori. ${ }^{5} \mathrm{H}$. pylori has been shown experimentally to colonise the stomachs of non-human primates, ${ }^{6}$ gnotobiotic pigs ${ }^{7,8}$ and dogs, ${ }^{9}$ animals which are expensive and difficult to maintain.

The establishment of a simple experimental model of infection with spiral bacteria in small laboratory animals could facilitate the understanding of many aspects of the relationship between spiral bacteria and the gastric mucosa. Fox et al. ${ }^{10}$ and Lee et al. ${ }^{11}$ have

Received 29 Sept. 1992; accepted 15 Dec. 1992.

* Correspondence should be sent to Dr D. M. M. Queiroz. proposed germ-free rats and mice colonised with $H$. felis, a tightly spiralled bacterium isolated from the stomachs of cats, as experimental models. Germ-free animals are also difficult to maintain but the stomachs of most conventional mice may be naturally colonised by another spiral bacterium, $H$. muridarum. ${ }^{12,13}$ This problem could be overcome by using conventional spiral bacteria-free animals obtained from conventional mouse colonies.

We have studied the histopathological response of conventionally maintained mice without gastric spiral bacteria and experimentally colonised with " $G$. suis" ${ }^{14}$ to evaluate it as a simple and inexpensive animal model for investigating the basis of spiral bacteria-associated gastritis in general, and of noncultivable spiral bacteria-associated gastritis in particular, since "G. suis" has not yet been cultivated. ${ }^{15}$

\section{Materials and methods}

\section{Animals}

Four-week-old CFW (LOB) axenic mice were obtained from the University of Notre Dame (France). They were maintained in conventional conditions and employed as matrices for the 61 4-week-old female mice used in this study. They had free access to water and a diet of sterile commercial food pellets. 


\section{Inocula}

Scrapings of gastric mucosa were obtained from the antral region of the stomach of " $G$. suis"-positive and -negative slaughtered pigs. Mucus from a "G. suis"positive pig was used only when a large number of tightly spiralled micro-organisms was observed on carbol fuchsin-stained smears and when the urease test was rapidly positive. Mucus was considered to be " $G$. suis"-negative when the results of both of these tests were negative. One part of the mucus was homogenised in three parts of saline $0.85 \%$ in a vortex blender and then used for mouse inoculation.

\section{Experimental design}

Fifty-five mice anaesthetised with ether were inoculated via a stomach tube with $0.2 \mathrm{ml}$ of the mucus homogenate as follows: 30 mice with mucus containing "G. suis" (test group) and 25 with mucus without "G. suis" (control group A). Six mice were not inoculated (control group B). All mice were maintained under the same conditions in separate cages.

Five test, four control group $\mathrm{A}$ and one control group B animals were killed by spinal dislocation 3, 7, $14,21,28$ and 60 days after inoculation. The stomachs were opened along the greater curvature and washed in saline $0.85 \%$.

\section{Histopathological examination}

Specimens of the oxyntic mucosa and strips of the gastric wall taken along the lesser curvature of the stomach from the terminal portion of the oesophagus to the duodenum of each animal were obtained. The fragments were fixed in Bouin's fluid for 18-24 h, dehydrated in an alcohol-xylene series and embedded in paraffin. Sections $4 \mu \mathrm{m}$ thick were stained with haematoxylin and eosin (H\&E) for histological examination and with carbol fuchsin for the identification of spiral bacteria. ${ }^{16}$

\section{Microbiological examination}

Fragments obtained from the membranous, antral and oxyntic gastric regions and from the duodenum were used for culture, urease test and carbol fuchsin staining. One specimen from each region was smeared on to a glass slide, heat fixed, stained with carbol fuchsin and examined under oil immersion for the presence of spiral bacteria. The specimen for the urease test was inserted into Christensen's urea $2 \%$ agar and examined within $24 \mathrm{~h} .{ }^{14}$ Specimens for culture were plated on to Belo Horizonte medium ${ }^{17}$ sheep blood agar and Skirrow's medium ${ }^{18}$ and incubated under aerobic, micro-aerophilic and anaerobic conditions, at $37^{\circ} \mathrm{C}$, for up to 7 days.

\section{Results}

\section{Microbiological examination}

Despite a detailed examination of the smears and histological sections, spiral bacteria were not found on the gastric and duodenal mucosa of any control mice. The results of the urease tests were also negative in these animals.

Tightly spiralled bacteria ("G. suis") were observed in smears of antral and oxyntic mucosa from all mice inoculated with mucus from "G. suis"'-positive pigs (fig. 1). The pre-formed urease test also gave a positive result in both regions. On the other hand, the urease test and carbol fuchsin-stained smears from fragments of the duodenum and the membranous portion gave negative results in all test mice. Spiral bacteria were not cultured from any region.

\section{Histopathological examination}

There were no inflammatory cells in the antral (fig. $2 a)$ or in the oxyntic mucosa (fig. 2b) of the majority of the control mice. In some animals there were only scarce mononuclear cells in the lower half of the gastric mucosa and in the submucosa of the transitional region between membranous and glandular portions of the stomach. No alteration was observed in glands or superficial epithelium. This histological pattern was considered normal and was similar to that observed in test mice examined 3 days after inoculation. Test animals examined 7, 14, 21, 28 and 60 days after inoculation had an inflammatory infiltrate of mononuclear cells, some neutrophils and a few eosinophils, mainly in the lower half of the antral mucosa (fig. 3) An inflammatory infiltrate with the same characteristics as described above was also

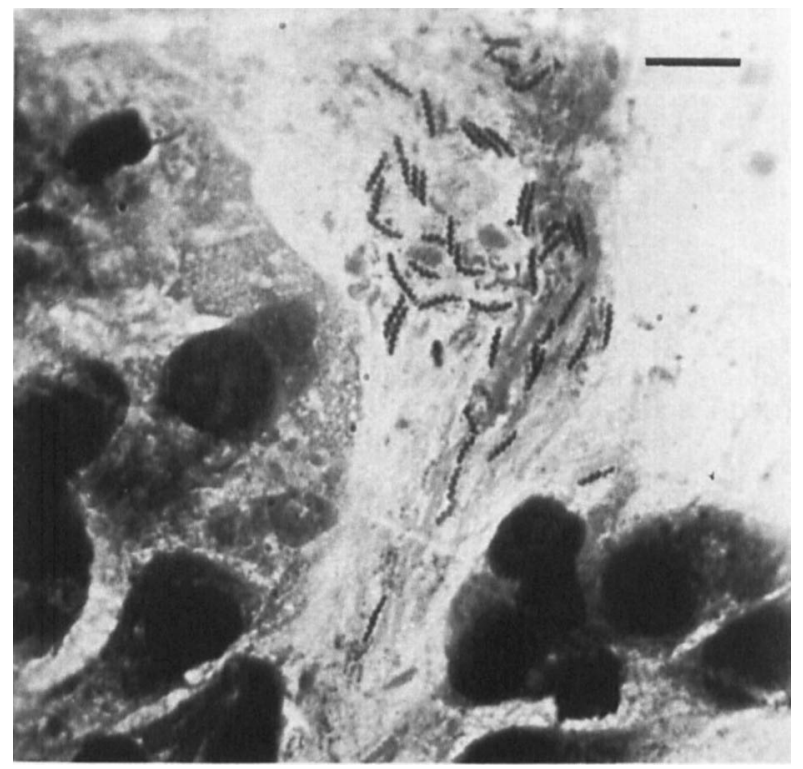

Fig. 1. Smear of antral mucosa of a test mouse showing numerous tightly spiralled bacteria. (Carbol fuchsin staining.) Bar $=8 \mu \mathrm{m}$. 

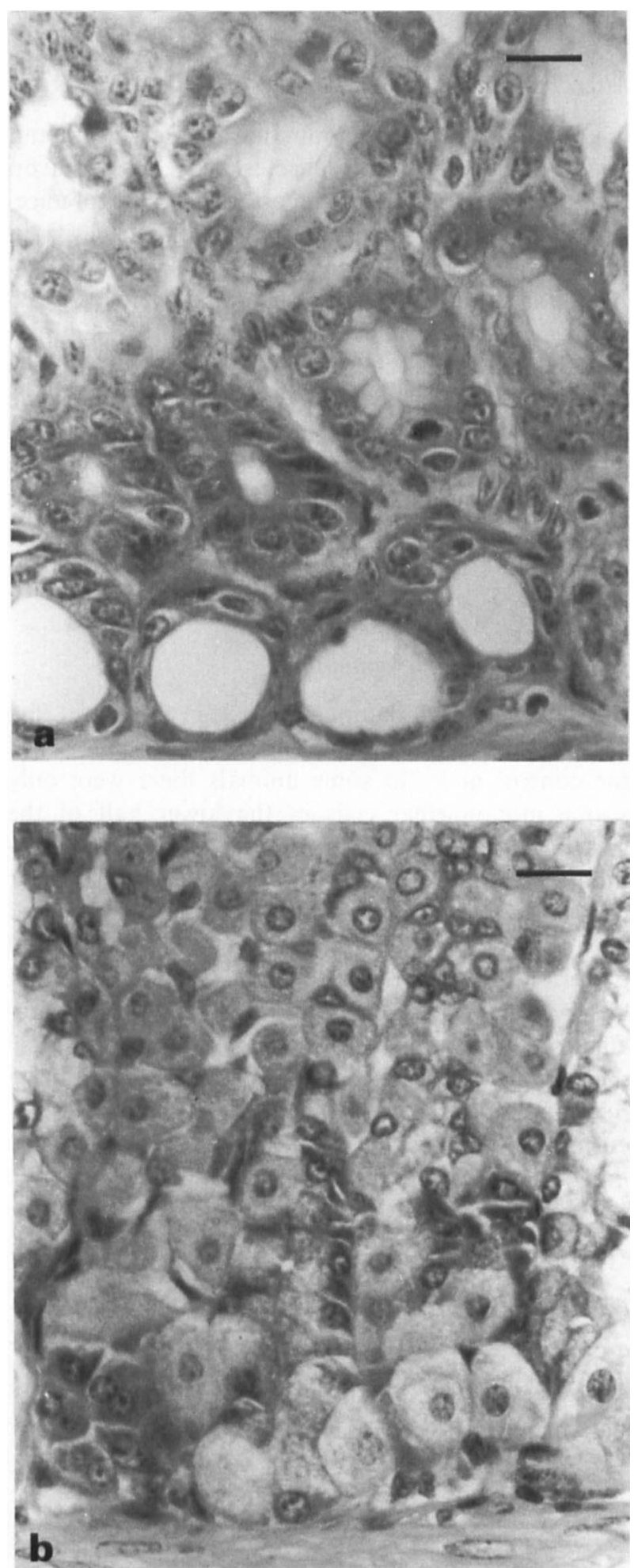

Fig. 2. a, Section of the antral mucosa of a control mouse (H\&E). Bar $=20 \mu \mathrm{m}$. b. Section of the oxyntic mucosa of a control mouse (H\&E). Bar $=20 \mu \mathrm{m}$.

present in the transitional region between the membranous and glandular portions from all test animals as well as in the oxyntic region (fig. 4) of animals examined 7, 14, 21 and 28 days after inoculation. Sixty days after inoculation the oxyntic mucosa showed oedema and epithelial degeneration but few inflammatory cells.

A large number of " $G$. suis" was present in sections

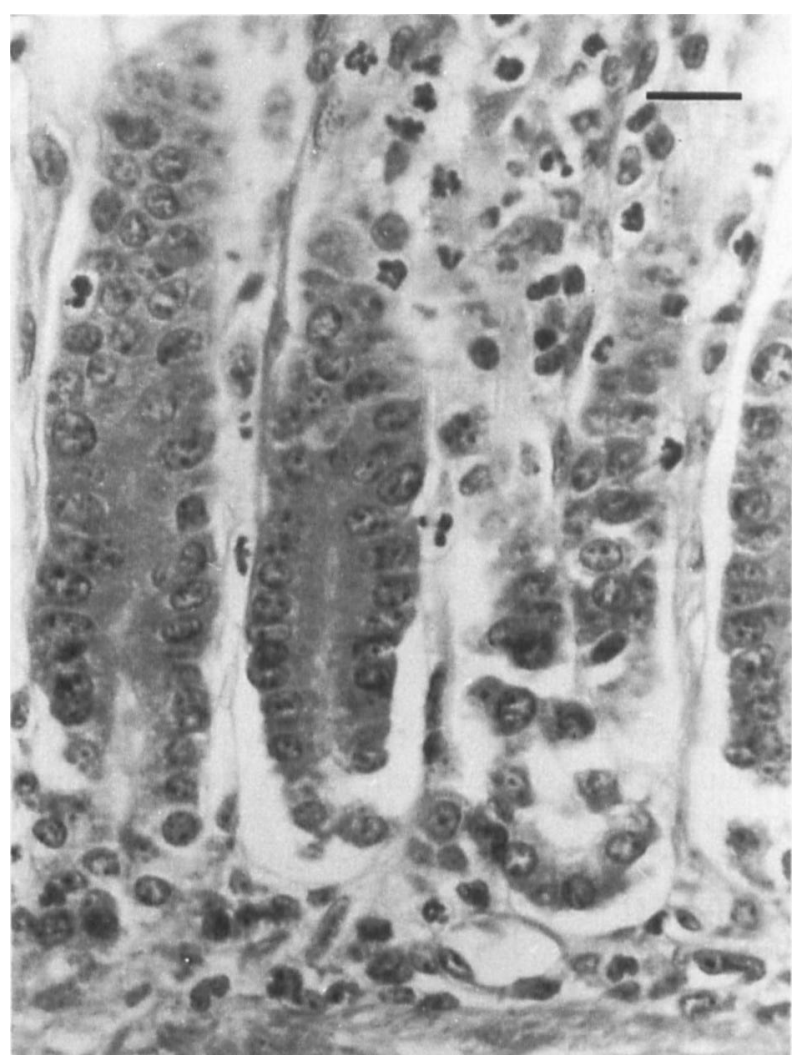

Fig. 3. Antral mucosa of a test mouse showing an inflammatory reaction with granulocytes and mononuclear inflammatory cells in the lamina propria $(\mathrm{H} \& \mathrm{E})$. Bar $=20 \mu \mathrm{m}$.

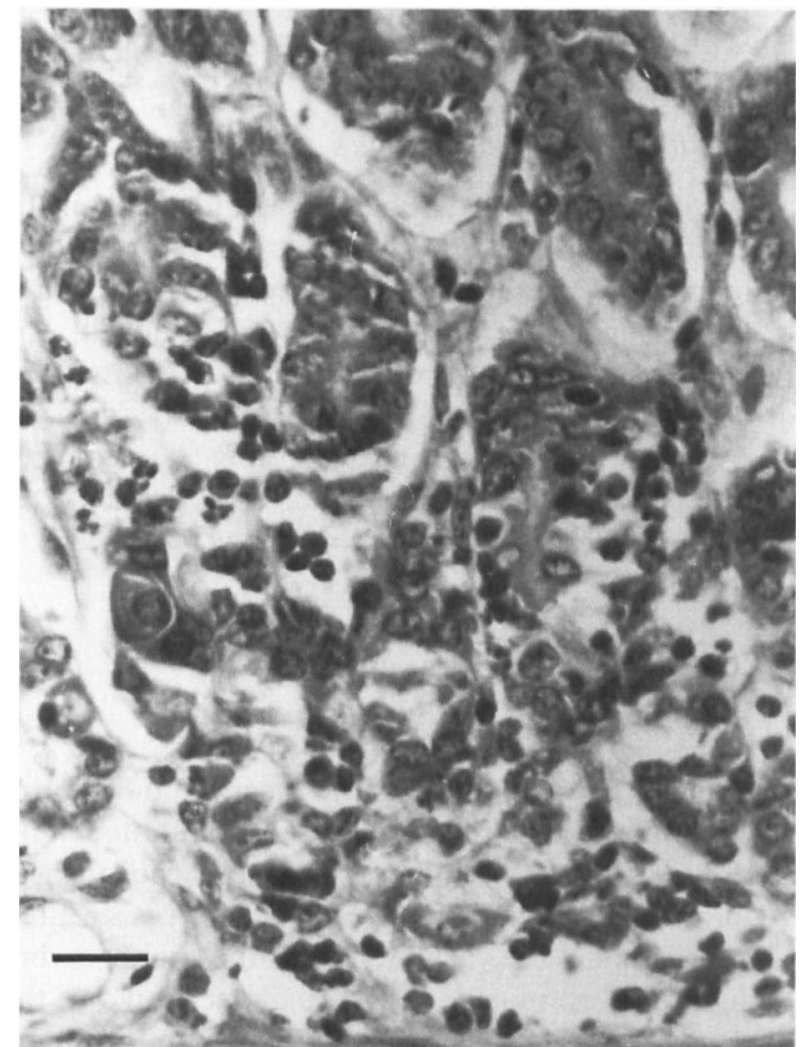

Fig. 4. Oxyntic mucosa of a test mouse showing inflammatory reaction with granulocytes and mononuclear inflammatory cells and some degree of glandular destruction (H\&E). Bar $=20 \mu \mathrm{m}$.

from the antral and oxyntic mucosa of test mice stained with carbol fuchsin. The bacteria were irregularly distributed in the mucus, in the mucosa of 
the gastric pits and in the oxyntic and antral glands, but were not observed in the lamina propria or submucosa. "G. suis" was not observed in fragments of the membranous portion and duodenum.

Spiral bacteria were not seen in the carbol fuchsinstained histological sections from control animals.

\section{Discussion}

Salomon, ${ }^{19}$ Kasai and Kobayashi ${ }^{20}$ and Weber et $a .^{21}$ have demonstrated that rodents could be colonised by non-species-specific gastric spiral bacteria. Recently, Dick et al., ${ }^{22}$ based on these previous studies, observed that non-cultivable tightly spiral gastric bacteria from man and non-human primates were able to colonise the gastric mucosa of mice. They proposed this procedure as a way of maintaining this group of gastric bacteria in vivo. Although the authors did not report histopathological alterations induced by these micro-organisms in the stomachs of the mice, they suggested that studies in mice colonised by spiral organisms could provide additional relevant data for our understanding of the pathogenic relationship between spiral micro-organisms and human gastritis. However, natural gastric colonisation by $H$. muridarum $^{12,13}$ could interfere with the results of experimental infection by other spiral bacteria. We have successfully overcome this problem by using $H$. muridarum-free mice.

We have observed previously a tightly spiralled bacterium associated with antral chronic gastritis in the gastric mucosa of pigs. ${ }^{14,15}$ This micro-organism could not be cultured despite numerous attempts with different laboratory media and growth conditions. ${ }^{15}$ For this reason, we have inoculated mice with porcine gastric mucus to grow the organism and to study its effect on the gastric mucosa.

All mice infected with "G. suis"-positive mucus were heavily and rapidly colonised. The microorganisms were located extracellularly and induced an inflammatory response in both antral and oxyntic mucosa. Although the inflammatory response was more accentuated in the lower half of the mucosa, the pattern of histological lesions was similar to that observed in pigs infected with " $G$. suis" ${ }^{15}$ Furthermore, the infection was not transient since the animals remained infected for a long period. These results strengthen the hypothesis that " $G$. suis" is a true pathogen.

The major problem in developing an animal model to study non-cultivable organisms resides in the fact that it is difficult to obtain and standardise the inoculum, since the organism cannot be grown in vitro. Thus, it is necessary to use mucus-containing suspensions as inoculum. However, until now it had not been determined if mucus itself causes any alterations in the gastric mucosa. Our results demonstrate that samples from mice inoculated with mucus without " $G$. suis" were histologically identical to those from uninoculated mice, showing that the mucus itself, or other bacteria present in it, do not cause an inflammatory response in the gastric mucosa of mice.

In conclusion, the use of conventionally housed mice obtained from germ-free mice matrices infected with G. suis should provide a useful model for the understanding of the pathogenesis of gastric infections caused by spiral bacteria.

This work was supported by CNPq, FINEP and FAPEMIG-Brasil. The authors thank the Laboratório de Nutrição e Gnotobiologia/Departamento de Bioquímica e Imunologia/ ICB/UFMG for kindly providing the mouse matrices.

\section{References}

1. Graham DY. Campylobacter pylori and peptic ulcer disease. Gastroenterology 1989; 96: 615-625.

2. Dent JC, McNulty CAM, Uff JC, Wilkinson SP, Gear MWL. Spiral organisms in the gastric antrum. Lancet 1987; 2: 96.

3. McNulty CAM, Dent JC, Curry A et al. New spiral bacterium in gastric mucosa. J Clin Pathol 1989; 42 : 585-591.

4. Solnick JV, O'Rourke J, Lee A, Tompkins LS. Gastrospirillum is a new species of Helicobacter in humans (Abstract). Gastroenterology 1992; 102 Suppl: A699.

5. Lee A. Spiral microorganisms: What are they? A microbiologic introduction to Helicobacter pylori. Scand J Gastroenterol 1991; 26 Suppl. 187: 9-22.

6. Newell DG, Hudson MJ, Baskerville A. Naturally occurring gastritis associated with Campylobacter pylori infection in the rhesus monkey. Lancet 1987; 2: 1338 .

7. Krakowka S, Morgan DM, Kraft WG, Leunk RD. Establishment of gastric Campylobacter pylori infection in the neonatal gnotobiotic piglet. Infect Immun 1987; 55: 2789-2796.

8. Jorgensen A, Egnstrand L, Soderlind O, Gustafsson S. Pig as a model for Campylobacter pylori infection. Abstracts of the 10th Congress International Pig Veterinary Society, 1988: 131 .
9. Radin MJ, Eaton KA, Krakowka S et al. Helicobacter pylori gastric infection in gnotobiotic beagle dogs. Infect Immun 1990; 58: 2606-2612.

10. Fox JG, Lee A, Otto G, Taylor NS, Murphy JC. Helicobacter felis gastritis in gnotobiotic rats: an animal model of Helicobacter pylori gastritis. Infect Immun 1991; 59: 785-791.

11. Lee A, Fox JG, Otto G, Murphy J. A small animal model of human Helicobacter pylori active chronic gastritis. Gastroenterology 1990; 99: 1315-1323.

12. Queiroz DMM, Contigli C, Coimbra RS et al. Spiral bacterium associated with gastric, ileal and caecal mucosa of mice. Lab Anim 1992; 26: 288-294.

13. Phillips MW, Lee A. Isolation and characterization of a spiral bacterium from the crypts of rodent gastrointestinal tracts. Appl Environ Microbiol 1983; 45: 675-683.

14. Queiroz DMM, Rocha GA, Mendes EN, Lage AP, Carvalho ACT, Barbosa AJA. Spiral microorganism in stomach of pigs. Vet Microbiol 1990; 24: 199-204.

15. Mendes EN, Queiroz DMM, Rocha GA et al. Histopathological study of porcine gastric mucosa with and without a spiral bacterium (Gastrospirillum suis). J Med Microbiol 1991; 35: 345-348.

16. Rocha GA, Queiroz DMM, Mendes EN, Lage AP, Barbosa AJA. Simple carbol fuchsin staining for showing $C$. pylori 
and other spiral bacteria in gastric mucosa. $J$ Clin Pathol 1989; 42: 1004-1005.

17. Queiroz DMM, Mendes EN, Rocha GA. Indicator medium for isolation of Campylobacter pylori. J Clin Microbiol 1987; 25: 2378-2379.

18. Skirrow MB. Campylobacter enteritis: a "new" disease. BMJ 1977; 2: 9-11.

19. Salomon H. Ueber das Spirillum des saugetiermagens under sein verhalten zu den belegzellen. Zentralbl Bakteriol Parasiterkd Infektionskr 1896; 19: 433-442.
20. Kasai $\mathbf{K}$, Kobayashi $\mathbf{R}$. The stomach spirochaete occurring in mammals. J Parasitol 1919; 6: 1-11.

21. Weber AF, Hasa O, Sutter JH. Some observations concerning the presence of spirilla in the fundic glands of dogs and cats. Am J Vet Res 1958; 19: 677-680.

22. Dick E, Lee A, Watson G, O'Rourke J. Use of the mouse for the isolation and investigation of stomach-associated, spiralhelical shaped bacteria from man and other animals. $J \mathrm{Med}$ Microbiol 1989; 29: 55-62. 